\title{
Metastatic Pancreatic Neuroendocrine Tumor that Progressed to Ectopic Adrenocorticotropic Hormone (ACTH) Syndrome with Growth Hormone-releasing Hormone (GHRH) Production
}

\author{
Rie Tadokoro ${ }^{1}$, Shotaro Sato ${ }^{1}$, Fumiko Otsuka ${ }^{1}$, Makoto Ueno ${ }^{2}$, Shinichi Ohkawa ${ }^{2}$, \\ Hideki Katakami ${ }^{3}$, Matsuo Taniyama ${ }^{1}$ and Shoichiro Nagasaka ${ }^{1}$
}

\begin{abstract}
The patient was a 61-year-old woman who had a well-differentiated pancreatic neuroendocrine tumor (PNET) with lymph node metastasis. After 15 months of octreotide treatment, glucose control deteriorated and pigmentation of the tongue and moon face developed, leading to the diagnosis of ectopic adrenocorticotropic hormone (ACTH) syndrome. An abnormal secretion of growth hormone $(\mathrm{GH})$ was identified, and the plasma growth hormone-releasing hormone (GHRH) level was elevated. A tumor biopsy specimen positively immunostained for ACTH and GHRH. Ectopic hormone secretion seems to have evolved along with the progression of the PNET.
\end{abstract}

Key words: GHRH, ACTH, ectopic hormone secretion, PNET

(Intern Med 55: 2979-2983, 2016)

(DOI: 10.2169/internalmedicine.55.6827)

\section{Introduction}

Pancreatic neuroendocrine tumors (PNETs) are derived from neuroendocrine cells of the pancreas. Tumors that synthesize and secrete biologically active hormones are called functional neuroendocrine tumors and all others are called non-functional neuroendocrine tumors (1). An epidemiological study conducted in Japan revealed the prevalence of PNET to be 2.23 per 100,000 people. Non-functional tumors were the most frequent, constituting $47.4 \%$ of all cases (2). The most frequent functional PNETs were insulinoma (38.2\%) and gastrinoma (7.9\%); glucagonoma and somatostatinoma were rare, with frequencies of 2.6 and $0.7 \%$, respectively (2). Ectopic adrenocorticotropic hormone (ACTH)-producing and growth hormone-releasing hormone (GHRH)-producing tumors are both very rare types of PNET.

We herein report a case of ACTH and GHRH producing
PNET presenting as Cushing's syndrome and an abnormal secretion of growth hormone (GH), following an initial diagnosis of a non-functional neuroendocrine tumor.

\section{Case Report}

The patient was a 61-year-old woman who became aware of abdominal pain in September 2009. A mass measuring 6 $\mathrm{cm}$ in diameter was noted in her pancreas (Fig. 1A). A biopsy of the pancreas was performed, and the diagnosis of a well-differentiated neuroendocrine tumor was made (Fig. 2A). The percentage of Ki67-positive cells was $11.5 \%$ (Fig. 2B), and these findings were consistent with the diagnosis of NET G2 (3). Since symptoms suggesting excessive hormone secretion, such as hypoglycemia, were lacking and the serum levels of insulin, gastrin and glucagon were all within the normal reference ranges $(17.4 \mu \mathrm{IU} / \mathrm{mL}, 80 \mathrm{pg} /$ $\mathrm{mL}$, and $130 \mathrm{pg} / \mathrm{mL}$, respectively), the patient was diagnosed as having a non-functional PNET. The results of other

\footnotetext{
${ }^{1}$ Department of Medicine, Division of Diabetes, Metabolism and Endocrinology, Showa University Fujigaoka Hospital, Japan, ${ }^{2}$ Division of Hepatobiliary and Pancreatic Medical Oncology, Kanagawa Cancer Center, Japan and ${ }^{3}$ Division of Clinical Research Sciences, Department of Medicine, Teikyo University Chiba Medical Center, Japan

Received for publication November 18, 2015; Accepted for publication February 28, 2016

Correspondence to Dr. Rie Tadokoro, rietado@med.showa-u.ac.jp
} 

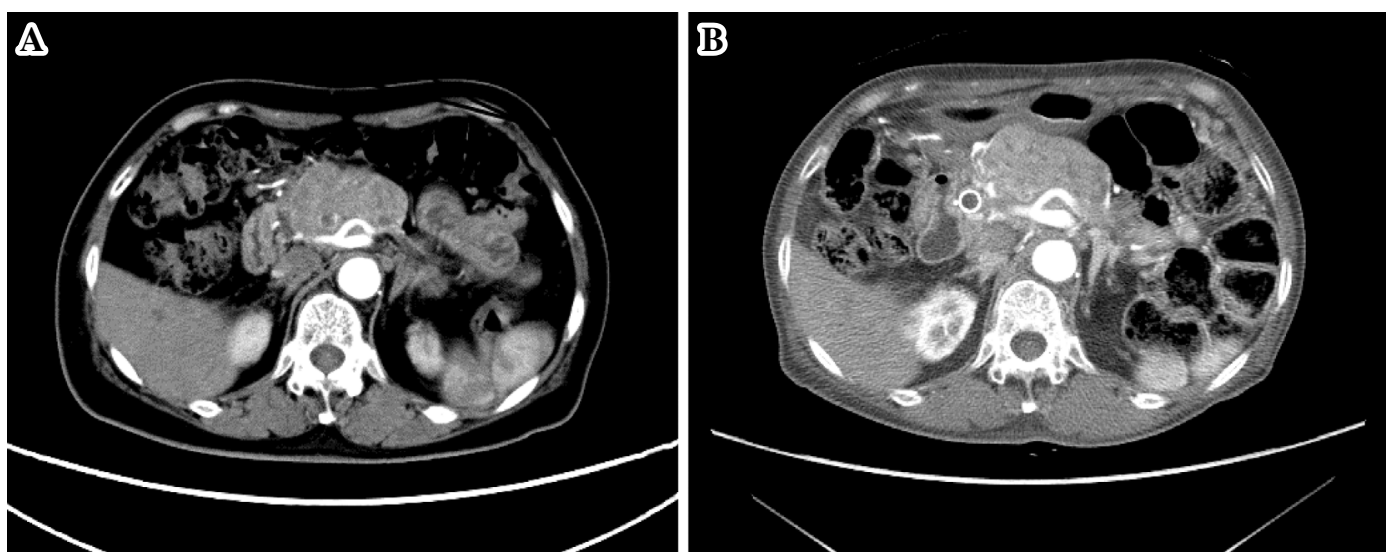

Figure 1. Computed tomography of the abdomen. An enhanced pancreatic tumor with metastasis to the para-aortic lymph nodes was demonstrated. A) Beginning of December, 2009. B) End of September, 2011.
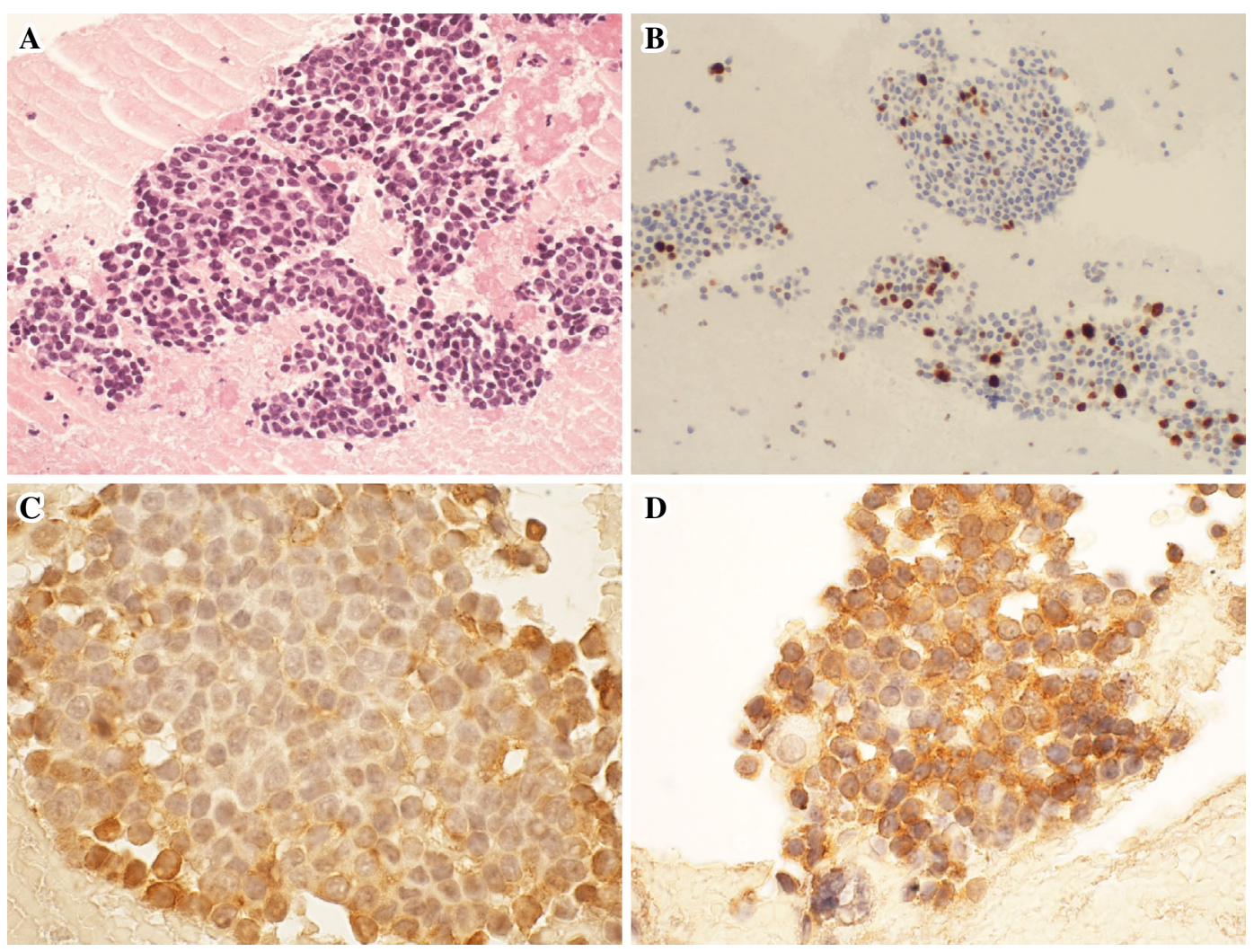

Figure 2. Pathological examination of the pancreatic tumor. A) Well-differentiated neuroendocrine tumor (Hematoxylin and Eosin staining). B) The percentage of Ki67 positive cells was 11.5\%. C) Positive immunostaining for ACTH. D) Positive immunostaining for GHRH. ACTH: adrenocorticotropic hormone, GHRH: growth hormone-releasing hormone

blood examinations were as follows: leukocyte count 4,700/ $\mu \mathrm{L}$, eosinophil fraction $0 \%$, lymphocyte fraction $33 \%$, serum potassium level $3.8 \mathrm{mEq} / \mathrm{L}$, and serum albumin level $4.1 \mathrm{~g} /$ dL. Although the eosinophil fraction was found to have decreased, the overall results, along with a lack of Cushingoid features on physical examination, were not indicative of hypercortisolemia. Due to the presence of distant lymph node metastases, surgery was not indicated, and instead, treatment with octreotide LAR $20 \mathrm{mg} / \mathrm{month}$ was initiated and continued.
In March 2011, the patient was admitted to our hospital to be treated for diabetes mellitus (HbA1c 9.9\%). The plasma level of ACTH (192.9 pg/mL; reference range, 7.263.3) was elevated, but the serum levels of cortisol $(10.4 \mu \mathrm{g} /$ $\mathrm{dL} ; 4.5-21.1)$, GH (0.99 ng/mL; $\leq 3.61)$, and insulin-like growth factor-1 (IGF-1) (85 ng/mL; 37-150) were within the normal reference ranges. In April 2011, the patient developed pigmentation of the tongue, and then moon face in the following month, leading to the suspicion of Cushing's syndrome. In September 2011, levels of ACTH, cortisol, GH 
Table 1. General Laboratory Data.

\begin{tabular}{lrllrlr}
\hline WBC & 3,900 & $/ \mu \mathrm{L}$ & Glucagon & 32 & $\mathrm{pg} / \mathrm{mL}$ & $(50-150)$ \\
$\mathrm{Hb}$ & 11.9 & $\mathrm{~g} / \mathrm{dL}$ & Gastrin & 313.1 & $\mathrm{pg} / \mathrm{mL}$ & $(0-200)$ \\
$\mathrm{Ht}$ & 34.9 & $\%$ & VIP & 23 & $\mathrm{pg} / \mathrm{mL}$ & $(0-100)$ \\
$\mathrm{PLT}$ & 150,000 & $/ \mu \mathrm{L}$ & ACTH & 205.9 & $\mathrm{pg} / \mathrm{mL}$ & $(7.2-63.3)$ \\
$\mathrm{TP}$ & 6.6 & $\mathrm{~g} / \mathrm{dL}$ & Cortisol & 15.2 & $\mu \mathrm{g} / \mathrm{dL}$ & $(4.5-21.1)$ \\
$\mathrm{Alb}$ & 3.7 & $\mathrm{~g} / \mathrm{dL}$ & DHEA-S & 160 & $\mu \mathrm{g} / \mathrm{dL}$ & $(12-133)$ \\
$\mathrm{BUN}$ & 11 & $\mathrm{mg} / \mathrm{dL}$ & GH & 4.08 & $\mathrm{ng} / \mathrm{mL}$ & $(\leq 3.61)$ \\
$\mathrm{UA}$ & 3.8 & $\mathrm{mg} / \mathrm{dL}$ & IGF-1 & 103 & $\mathrm{ng} / \mathrm{mL}$ & $(37-150)$ \\
$\mathrm{Cre}$ & 0.56 & $\mathrm{mg} / \mathrm{dL}$ & GHRH & $9,230.4$ & $\mathrm{pg} / \mathrm{mL}$ & $(4-14)$ \\
$\mathrm{Na}$ & 142 & $\mathrm{mEq} / \mathrm{L}$ & PRL & 13.3 & $\mathrm{ng} / \mathrm{mL}$ & $(3.5-32.7)$ \\
$\mathrm{Cl}$ & 103 & $\mathrm{mEq} / \mathrm{L}$ & TSH & 2.031 & $\mu \mathrm{IU} / \mathrm{mL}$ & $(0.30-4.5)$ \\
$\mathrm{K}$ & 2.6 & $\mathrm{mEq} / \mathrm{L}$ & free T4 & 0.84 & $\mathrm{ng} / \mathrm{dL}$ & $(0.7-1.8)$ \\
$\mathrm{Ca}$ & 8.4 & $\mathrm{mg} / \mathrm{dL}$ & FSH & 96.3 & $\mathrm{mIU} / \mathrm{mL}$ & $(10.5-142.8)$ \\
Fasting glucose & 184 & $\mathrm{mg} / \mathrm{dL}$ & LH & 32.2 & $\mathrm{mIU} / \mathrm{mL}$ & $(13.3-61.6)$ \\
HbAlc & 9.9 & $\%$ & UFC & 86.1 & $\mu \mathrm{g} / \mathrm{day}$ & $(11.2-80.3)$ \\
\hline
\end{tabular}

VIP: vasoactive intestinal peptide, DHEA-S: dehydroepiandrosterone sulfate, GH: growth hormone, IGF-1: insulin-like growth factor-1, PRL: prolactin, TSH: thyroid stimulating hormone, FSH: follicle stimulating hormone, LH: luteinizing hormone, UFC: urinary free cortisol excretion

Table 2. Endocrinology Examinations.

\begin{tabular}{|c|c|c|c|c|c|}
\hline \multicolumn{6}{|c|}{ Diurnal changes in ACTH and cortisol levels } \\
\hline & Morning & 11 p.m & & & \\
\hline $\mathrm{ACTH}(\mathrm{pg} / \mathrm{mL})$ & 205.9 & 221.4 & & & \\
\hline cortisol $(\mu \mathrm{g} / \mathrm{dL})$ & 15.2 & 13.3 & & & \\
\hline \multicolumn{6}{|c|}{ Overnight $8 \mathrm{mg}$ DST } \\
\hline ACTH (pg/mL) & 312.8 & & & & \\
\hline Cortisol $(\mu \mathrm{g} / \mathrm{dL})$ & 20.0 & & & & \\
\hline \multicolumn{6}{|c|}{ CRH stimulation test } \\
\hline & $0 \mathrm{~min}$ & $30 \mathrm{~min}$ & $60 \mathrm{~min}$ & $90 \mathrm{~min}$ & \\
\hline $\mathrm{ACTH}(\mathrm{pg} / \mathrm{mL})$ & 188.2 & 141.4 & 146.9 & 139.3 & \\
\hline Cortisol $(\mu \mathrm{g} / \mathrm{dL})$ & 12.3 & 14.0 & 14.2 & 14.1 & \\
\hline \multicolumn{6}{|c|}{ TRH stimulation test } \\
\hline & $0 \mathrm{~min}$ & $30 \mathrm{~min}$ & $60 \mathrm{~min}$ & $90 \mathrm{~min}$ & $120 \mathrm{~min}$ \\
\hline $\mathrm{TSH}(\mu \mathrm{IU} / \mathrm{mL})$ & 2.36 & 26.84 & 26.74 & 21.62 & 17.86 \\
\hline $\mathrm{GH}(\mathrm{ng} / \mathrm{mL})$ & 4.14 & 22.12 & 13.89 & 8.55 & 5.08 \\
\hline PRL (ng/mL) & 9.1 & 158.3 & 128.2 & 88.6 & 61.5 \\
\hline
\end{tabular}

DST: dexamethasone suppression test, $\mathrm{CRH}$ : corticotrophin-releasing hormone, TRH: thyrotropin-releasing hormone

and IGF-1 were elevated to $249.1 \mathrm{pg} / \mathrm{mL}, 17.6 \mu \mathrm{g} / \mathrm{dL}, 11.6$ $\mathrm{ng} / \mathrm{mL}$, and $148 \mathrm{ng} / \mathrm{mL}$, respectively. The patient was readmitted to our department. The patient had no family history of multiple endocrine neoplasia (MEN) or any other endocrine disorders.

On admission, her height was $147.5 \mathrm{~cm}$ and weight 45.15 $\mathrm{kg}$. Her blood pressure was $140 / 86 \mathrm{mmHg}$ and body temperature was $36.5^{\circ} \mathrm{C}$. Moon face and pigmentation of the tongue were noted. Clinical features of acromegaly were lacking. A left supraclavicular lymph node was palpable.

The patient's general laboratory data are shown in Table 1. Hypokalemia, and elevated fasting glucose and HbA1c levels were noted. Plasma ACTH was as high as $205.9 \mathrm{pg} / \mathrm{mL}$, and the urinary excretion of cortisol had also increased.
Endocrinological examinations revealed the lack of any diurnal changes in ACTH and cortisol levels, and those levels were not suppressed in response to the overnight dexamethasone ( $8 \mathrm{mg}$ ) suppression test (Table 2). The plasma ACTH levels did not respond to an intravenous corticotrophin-releasing hormone challenge. These results were consistent with the diagnosis of ectopic ACTHproducing syndrome. The serum GH levels were modestly elevated (Table 1, 2) despite hyperglycemia, and paradoxically responded to an intravenous thyrotropin-releasing hormone (TRH) challenge (Table 2). The plasma levels of GHRH were as high as 9,230.4 pg/mL (reference range, 4 14) (4) (Table 1).

Pituitary magnetic resonance imaging (MRI) revealed no abnormalities. Computed tomography (CT) of the abdomen revealed a progressive enlargement of the pancreatic tumor with metastases to the para-aortic lymph nodes (Fig. 1B). No liver metastasis was observed, but the decrease in visceral and subcutaneous and fat area was apparent as compared to the previous CT (Fig. 1).

Re-examination of the biopsied specimen of pancreatic tissue obtained at first diagnosis revealed positive immunostaining for ACTH (Fig. 2C) and GHRH (Fig. 2D).

Octreotide LAR was continued, and metyrapone was administered to reduce hypercortisolemia. However, the tumors gradually increased in size. The patient was hospitalized in May 2012 for cholecystitis and peritonitis and was treated at that time by intraperitoneal drainage. Subsequently, the tumor perforated into the intestine, and palliative care was begun. In the fall of 2012, the patient died; an autopsy was not performed.

In this case, genetic testing for MEN type 1 (MEN-1) and related abnormalities was not performed. 
Table 3. Ectopic Secretion of ACTH and GHRH by a Neuroendocrine Tumor: 6 Patients.

\begin{tabular}{cccccccc}
\hline Age & Gender & Origin & $\begin{array}{c}\text { GHRH } \\
(\mathrm{pg} / \mathrm{mL})\end{array}$ & $\begin{array}{c}\text { ACTH } \\
(\mathrm{pg} / \mathrm{mL})\end{array}$ & Cortisol $(\mu \mathrm{g} / \mathrm{dL})$ & $\begin{array}{c}\text { Acromegalic } \\
\text { feature }\end{array}$ & Cushingoid feature \\
\hline 41 & F & Pancreas & GRF10,000 & 194 & $22.8 \sim 61.2$ & - & + \\
18 & M & Foregut & GHRF + & 1,500 & 42.2 & + & + \\
23 & M & Lung & 45,000 & 300 & 36.8 & + & + \\
49 & M & Thymus & $699 \sim 1,500$ & $200 \sim 250$ & $54.3 \sim 65.2$ & - & + \\
37 & F & Thymus & $2,245.8$ & $169.6 \sim 205.2$ & $13.3 \sim 24.4$ & - & + \\
61 & F & Pancreas & $9,230.4$ & 205.9 & 15.2 & - & + \\
\hline
\end{tabular}

The last case is the present case.

\section{Discussion}

Initially, the present patient appeared to have a nonfunctioning PNET, but from the findings of deterioration of glucose control, tongue pigmentation and moon face, the diagnosis of ectopic ACTH-producing syndrome was made. In addition, an abnormal secretion of GH was demonstrated, possibly due to ectopic GHRH secretion. Immunostaining of the pancreatic specimen obtained at first diagnosis suggested that the PNET had been producing and secreting these hormones simultaneously.

In the present case, because the clinical features of Cushing's syndrome or acromegaly were lacking at first presentation, detailed investigations were not performed at that time. Along with the progressive enlargement of the tumor (Fig. 1), clinical manifestations of Cushing's syndrome and an abnormality of GH secretion became apparent. It is conceivable that there may have been a subtle hormone excess at the initial presentation, and that the increase in tumor mass could have resulted in the development of more apparent manifestations of hormone excess.

Neuroendocrine tumors often produce and secrete multiple hormones (2). However, tumors simultaneously producing GHRH and ACTH are very rare. Only five cases have been reported, as far as we could determine based on a search of the pertinent literature (5-9), and the present case is the second reported case derived from a primary pancreatic tumor (Table 3). Cushingoid features were evident in all these cases, but features of acromegaly were present in only two cases. It is conceivable that some PNETs may simultaneously produce GHRH and ACTH on a subclinical level, as this phenomenon has not yet been thoroughly investigated.

In ectopic ACTH syndrome cases, small-cell carcinoma of the lung is most frequently observed, and pancreatic tumors account for only $10 \%$ of the cases (10). In cases of ectopic ACTH syndrome caused by PNET, many are aggressive and the prognosis is poor $(11,12)$. In ectopic ACTH syndrome, increased visceral fat associated with hypercortisolemia is observed in slowly progressive cases, whereas weight loss and cachexia are prominent features in rapidly progressive cases of tumors, such as small-cell carcinoma of the lung (10). In the present case, the progressive clinical course precluded some of the more common physical manifestations of hypercortisolemia; indeed, findings of decreased visceral and subcutaneous fat (Fig. 1B) were accompanied by the progression of ectopic ACTH syndrome.

Ectopic acromegaly caused by GHRH-producing tumors is rare. To the best of our knowledge, only 74 (13) and 99 (14) cases have been reported previously. Primary tumors are most commonly found in the lung, followed by the pancreas, with frequency of $25 \%$ (13) or $33 \%$ (14). Other tumors include those of the digestive tract, pheochromocytomas, and tumors of the thymus. Most of the reported cases of ectopic acromegaly were detected and diagnosed due to clinically evident acromegalic features of varying intensity. The reported latent period to display clinical signs of active acromegaly was as long as 8.3 years (14). However, some of these tumors had modest levels of GHRH production and secretory functions. Such cases may not develop acromegaly due to modest GHRH production and secretion, or no GHRH secretion despite GHRH production (13).

In patients with ectopic acromegaly, the serum GH levels after an oral glucose challenge may show a paradoxical increase, and those levels often display a paradoxical increase to a TRH challenge $(14,15)$. In the present case also, the serum GH levels were not suppressed despite hyperglycemia, and a TRH challenge revealed a paradoxical GH increase. These results are clinically consistent with acromegaly, but no clinical features of acromegaly were present in this patient. This may have been due to the short duration of the disease.

Mutations in the MEN1 gene are found in approximately $10 \%$ of functional PNET cases (2). However, this was unlikely in the present case because of the absence of any findings suggesting hyperparathyroidism, the normal pituitary MRI findings, and the lack of a family history of endocrine disorders; therefore, genetic testing for MEN-1 was not performed.

In conclusion, in cases of PNET, it appears to be important to carry out detailed investigations to reveal the entire extent of endocrinology disturbances.

The authors state that they have no Conflict of Interest (COI).

\section{References}

1. Plöckinger U, Rindi G, Arnold R, et al. Guidelines for the diagnosis and treatment of neuroendocrine gastrointestinal tumours. Neuroendocrinology 80: 394-424, 2004. 
2. Ito T, Sasano H, Tanaka M, et al. Epidemiological study of gastroenteropancreatic neuroendocrine tumors in Japan. J Gastroenterol 45: 234-243, 2010.

3. Bosman FT, Carneiro F, Hruban RH, et al. WHO Classification of Tumours of the Digestive System (World Health Organization Classification of Tumours). IARC Press, Lyon, 2010.

4. Katakami H, Hashida S, Hidaka H, Ishikawa E, Matsukura S. Development and clinical application of a highly sensitive enzyme immunoassay (EIA) for human growth hormone-releasing hormone (hGHRH) in plasma. Endocrine J 45: S67-S70, 1998.

5. Sasaki A, Sato S, Hanew K, et al. A case of ectopic ACTH syndrome associated with GRF secreting pancreatic tumor. Igakunoayumi (Journal of Clinical and Experimental Medicine) 141: 327-330, 1987 (Abstract in Japanese).

6. Leveston SA, McKeel DW Jr, Buckley PJ, et al. Acromegaly and Cushing's syndrome associated with a foregut carcinoid tumor. J Clin Endocrinol Metab 53: 682-689, 1981.

7. Southgate HJ, Archbold GP, el-Sayed ME, Wright J, Marks V. Ectopic release of GHRH and ACTH from an adenoid cystic carcinoma resulting in acromegaly and complicated by pituitary infarction. Postgrad Med J 64: 145-148, 1988.

8. Jansson JO, Svensson J, Bengtsson BA, et al. Acromegaly and Cushing's syndrome due to ectopic production of GHRH and ACTH by a thymic carcinoid tumour: in vitro responses to GHRH and GHRP-6. ClinEndocrinol (Oxf) 48: 243-250, 1998.

9. Tanaka S, Hiduka N, Tanabe M, et al. An ACTH-producing malig- nant thymic carcinoid complicated by a GHRH-producing tumor (abstract). Nihon Naibunpi Gakkai Zasshi (Folia Endocrinol Jap) 85: 194, 2009 (in Japanese).

10. Wajchenberg BL, Mendonca BB, Liberman B, et al. Ectopic adrenocorticotropic hormone syndrome. Endocr Rev 15: 752-787, 1994.

11. Patel FB, Khagi S, Daly KP, Lechan RM, Ummaritchot V, Saif MW. Pancreatic neuroendocrine tumor with ectopic adrenocorticotropin production: a case report and review of literature. Anticancer Res 33: 4001-4005, 2013.

12. Kondo $\mathrm{T}$, Matsuyama $\mathrm{R}$, Ashihara $\mathrm{H}$, et al. A case of ectopic adrenocorticotropic hormone-producing pancreatic neuroendocrine tumor with multiple liver metastases. Endocr J 57: 229-236, 2010.

13. Borson-Chazot F, Garby L, Raverot G, et al. Acromegaly induced by ectopic secretion of GHRH: a review 30 years after GHRH discovery. Ann Endocrinol (Paris) 73: 497-502, 2012.

14. Ghazi AA, Amirbaigloo A, Dezfooli AA, et al. Ectopic acromegaly due to growth hormone releasing hormone. Endocrine 43: 293-302, 2013.

15. Faglia G, Arosio M, Bazzoni N. Ectopic acromegaly. Endocrinol Metab Clin North Am 21: 575, 1992.

The Internal Medicine is an Open Access article distributed under the Creative Commons Attribution-NonCommercial-NoDerivatives 4.0 International License. To view the details of this license, please visit (https://creativecommons.org/licenses/ by-nc-nd/4.0/).

(C) 2016 The Japanese Society of Internal Medicine http://www.naika.or.jp/imonline/index.html 